\title{
Análisis aplicativo de mecanismos para la recuperación de oro y polimetálicos, en el ámbito de la pequeña minería y minería artesanal en Ecuador, amigables con el medio ambiente.
}

DOI: https://doi.org/10.33262/ap.v3i3.1.92

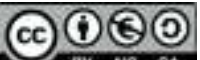

Implementation of environmentally friendly mechanisms for the recovery of Gold and polymetallic in the field of small mining and artisanal mining in Ecuador

Jenny Priscila Granja Carrera. ${ }^{1}$, Christian Adrián Ordoñez Guaycha. ${ }^{2}$ \& Gregory Guillermo Cuesta Andrade. ${ }^{3}$

\begin{abstract}
.
Introduction. Ecuador has great mining potential that is affected by poor practice in mineral extraction causing serious damage to the environment, which is why this research topic is raised. Objective. Document the different techniques and mechanisms friendly to the environment for the recovery of gold and polymetallic in the field of small mining and artisanal mining, through the analysis of mineral extraction alternatives for its proposal and implementation in small-scale mining. Methodology. Documentary or bibliographic research will be applied that, through digital media, from documentary sources, books, scientific articles, and hemerography, information is obtained, selected,

\footnotetext{
${ }^{1}$ Escuela Superior Politécnica de Chimborazo, Grupo de Investigación de Recursos Mineros e Ingeniería, Morona Santiago, jenny.granja@espoch.edu.ec. https://orcid.org/0000-0003-4005-3687. https://orcid.org/0000-0003-4005-3687

${ }^{2}$ Escuela Superior Politécnica de Chimborazo, Grupo de Investigación de Recursos Mineros e Ingeniería, Morona Santiago, cordoniez@espoch.edu.ec, https://orcid.org/0000-0003-0111-8476

${ }^{3}$ Escuela Superior Politécnica de Chimborazo, Grupo de Investigación de Recursos Mineros e Ingeniería, Morona Santiago, gregory.cuesta@espoch.edu.ec, https://orcid.org/0000-0002-9308-0593
} 
compiled, organized, interpreted and analyzed to later capture, structure and present the work done. Results. There are several extraction methods and techniques that help reduce the amount of mercury and cyanide used in the gold recovery process, classified as physical, chemical and biological, of which the most appropriate, viable and feasible are chosen and analyzed, with the least impact on the environment and human beings.

Keywords: Extraction Methods, gold, mercury, cyanide, sustainable mining

\section{Resumen.}

Introducción. El Ecuador tiene gran potencial minero que se ve afectado por la mala práctica en la extracción mineral ocasionando graves daños en el medioambiente, por lo cual se plantea este tema de investigación. Objetivo. Documentar las diferentes técnicas y mecanismos amigables con el medio ambiente para la recuperación del oro y polimetálicos en el ámbito de la pequeña minería y minería artesanal, mediante el análisis de alternativas de extracción mineral para su propuesta e implementación en la minería a pequeña escala. Metodología. Se aplicará la investigación documental o bibliográfica que, a través de medios digitales, a partir de fuentes documentales, libros, artículos científicos, y hemerografía, se obtiene, selecciona, compila, organiza, interpreta y analiza la información para posteriormente plasmar, estructurar y presentar el trabajo realizado. Resultados. Existen varios métodos y técnicas de extracción que ayudan a la disminución de la cantidad de mercurio y cianuro utilizado en el proceso de recuperación de oro, clasificadas como físicas, químicas y biológicas, de los cuales se escogen y analizan los más adecuados, viables y factibles, con la menor afectación en el medioambiente y ser humano.

Palabras claves: Métodos de extracción, oro, mercurio, cianuro, minería sustentable.

\section{Introducción.}

La minería constituye un pilar fundamental dentro de la economía de muchos países, y se ha ido desarrollando significativamente. No obstante, esta actividad tiene importantes repercusiones, pues su creciente práctica se ha tornado hostil, generando problemas medioambientales y socioeconómicos.

En Ecuador la industria minera ha ido tomando fuerza en los últimos años, despertando el interés de los individuos por la extracción de minerales metálicos (oro, plata), siendo el Estado Ecuatoriano el responsable de su regulación. Sin embargo, se ha otorgado permisos a las comunidades para la explotación de minerales, bajo la modalidad de minería artesanal, quienes realizan la extracción de forma empírica, sin un estudio técnico previo (Tsenkush Chamik, 2016). Los gastos en remediación ambiental y tecnologías innovadoras que ayudan al procesamiento de minerales generan costos que los mineros artesanales no están dispuestos a cubrir, incluso el coste de la protección de la salud y la 
seguridad de los mineros es un factor crítico (Enciclopedia de Salud y Seguridad en el Trabajo, 2018). Asimismo, las escasas medidas de control ambiental han provocado el deterioro de los recursos naturales como el agua (López y Moreno, 2018).

El mercurio y el cianuro en la industria minera son muy comunes para la extracción del oro, asimismo son consideradas de alta contaminación y toxicidad. El mercurio es un elemento pesado, el cual tiene gran afinidad con el oro y por ende puede utilizarse para formar una amalgama. El mercurio al ser elemental no se puede descomponer o destruir y permanece en el ambiente a largo plazo, ocasionando un daño ambiental imposible de remediar (Murillo y Gazel, 2019). Por otro lado, tenemos al cianuro que es un compuesto químico que contiene carbono, y nitrógeno. En la industria mineral comúnmente se utiliza cianuro de sodio, el cual se transporta en estado sólido hasta la mina y luego se disuelve en agua. El oro que está en la roca molida se une al cianuro y el sodio y se separa de los demás minerales. En la industria mineral responsable el cianuro se recicla en la misma mina, y si es necesario se trata mediante procesos químicos o se degrada mediante procesos naturales. El cianuro no es persistente como el mercurio, y es por esta propiedad es que es preferido en la industria minera (Murillo y Gazel, 2019). Sin embargo, en un proceso de recuperación de oro en minerales compuestos por sulfuros, generan diversos problemas ambientales, por los procesos de cianuración, es por eso que el procesar estos materiales se requiere un pretratamiento, en la cual el cianuro destruye la matriz sulfurada y libera el oro que se encuentra atrapado en ella. (Abad Rominger, 2020)

Con estos antecedentes se procura documentar diferentes técnicas para el reemplazo de sustancias nocivas para el medio ambiente en la extracción de oro y polimetálicos en el ámbito de la pequeña minería y minería artesanal y su implementación en la industria.

\section{Problema}

Los problemas de afectación al medio ambiente es un tema de interés de todos, así mismo la minería es una actividad inevitable y necesaria para el ser humano. En las últimas décadas se ha satanizado la actividad minera, llegando a extremos por ambas partes. Y por un lado se tiene, el aumento de la minería ilegal que no se responsabiliza por los daños que pueda causar al medio ambiente, y por otro los pseudo - ambientalistas que se oponen rotundamente a la minería ocasionando la no inversión de capitales nacionales y extranjeros. Estos dos extremos provocan discusión y desacuerdos.

Ecuador está en la vía al desarrollo minero pero las políticas y la sociedad ecuatoriana no permiten un óptimo crecimiento del mismo. En el modelo de pequeña minería y minería artesanal, se deben adoptar medidas de cambio, para tener un modelo de minería sostenible, con una nueva ley que posea una estructura altamente técnica en donde se puede desarrollar una industria minera responsable, que en lugar de dejar daños irreparables al medio ambiente deje beneficios a nuestro país. (Murillo y Gazel, 2019).

Por lo tanto, la documentación de varias técnicas amigables para luego llevarlo a la práctica con la implementación de alguno de estos mecanismos para la recuperación de 
Oro y polimetálicos en la pequeña minería y minería artesanal ayudarán significativamente a disminuir los niveles de contaminación.

$\mathrm{Al}$ ser un proyecto investigativo bibliográfico se pretende llegar a todo el sector minero con propuestas técnicas viables para un manejo amigable de los recursos minerales.

\section{Objetivos}

Documentar diferentes técnicas y mecanismos amigables con el medio ambiente para la recuperación del oro y polimetálicos en el ámbito de la pequeña minería y minería artesanal, mediante el análisis de alternativas de extracción mineral para su propuesta e implementación en la minería a pequeña escala.

\section{Objetivos específicos:}

- Analizar variables operacionales de diferentes técnicas que permitan la recuperación de oro y polimetálicos aplicando una tecnología limpia, sin contaminación por mercurio y cianuro.

- Proponer la implementación de estas técnicas dentro de la actividad minera artesanal y a pequeña escala.

\section{Metodología}

La metodología que se aplica es la investigación documental o bibliográfica que, a través de medios digitales a partir de fuentes documentales, libros, artículos científicos, y hemerografía se obtiene, selecciona, compila, organiza, interpreta y analiza la información para posteriormente plasmar, estructurar y presentar el trabajo realizado (Rizo Maradiaga, 2015).

Para efecto de esta investigación se divide en cuatro etapas:

1. Planeación

2. Recolección y selección de información

3. Procesamiento de la información documental

4. Redacción y presentación del trabajo de investigación

Planeación, consiste en seleccionar, plantear y delimitar el tema; elaborar un plan, esquema y agenda de trabajo. Dentro de las actividades a realizar en la planificación están:

- Investigar algunas técnicas de extracción viables y amigables con el medio ambiente.

- Seleccionar las mejores técnicas.

- Redacción del trabajo investigativo, realizando un esquema de la redacción.

Recolección de la información con la lectura de documentos, acopio de información. Es necesario clasificar la información de acuerdo con el grado de importancia en documentos primarios, secundarios y terciarios (Rizo Maradiaga, 2015). 
Lo primero es excluir de la recopilación:

- páginas primariamente comerciales

- basadas en investigación escasa o poco fundamentada

- ausencia de un patrocinador claramente identificado

- ausencia de contenidos suficientes sobre el tema

De acuerdo con el contenido de la información este debe ser de actualidad, de fácil acceso, con un enfoque práctico y profesional de investigación.

Procesamiento de la información implica el análisis, interpretación y clasificación, para esto es necesario una buena lectura con un entendimiento profundo para seleccionar las ideas y elementos indispensables. Es necesario ir tomando notas y subrayando las ideas principales y temas de interés de la investigación.

Redacción y presentación del trabajo de investigación involucra utilizar técnicas de redacción y estructura del trabajo. Para la redacción científica es indispensable precisión, claridad, y brevedad con la finalidad de comunicar el conocimiento científico.

\section{Importancia}

Dentro de la sociedad ecuatoriana se ha insertado un pensamiento muy extremista, oponiéndose totalmente a la actividad minera. Es cierto que a lo largo de los años los asentamientos mineros han generado contaminación de las aguas por las emisiones de mercurio, también cabe recalcar que esta actividad no tenía un control por parte del Estado, los esfuerzos para llevar a cabo una minería sustentable han sido deficientes.

Actualmente, el sector minero forma parte de los planes y programas estratégicos del Estado, permitiendo de tal manera cumplir y exigir los compromisos adquiridos con responsabilidad ambiental para mejorar la calidad de vida de las personas.

Lo que se busca es cambiar los métodos de extracción que son nocivos para la vida y reemplazarlos con otras técnicas o mecanismos que cumplen las mismas funciones de recuperación mineral, sin generar problemas ambientales y sociales. La minería es necesaria para la vida del ser humano, por lo tanto, existe un gran interés por desarrollar una minería que reduzca la contaminación y a su vez, fomente el desarrollo sostenible (López y Moreno, 2018).

La necesidad de implementar técnicas o mecanismos amigables con el medio ambiente para la recuperación del oro y polimetálicos en el ámbito de la pequeña minería y minería artesanal hace inevitable el desarrollo de esta investigación. La tecnología avanza a diario y se tiene acceso a mucha información científica comprobada, en este sentido el tema investigativo es de interés mundial, con el fin de mejorar la calidad de vida y recomendar ciertas prácticas eficientes para la extracción de oro y polimetálicos teniendo en cuenta el medio ambiente, el desarrollo económico, desarrollo social y sobre todo que sea aplicable en el Ecuador. 


\section{Minería en el Ecuador}

Ecuador tiene gran potencial minero, principalmente en zonas de Manabí, Esmeraldas, Azuay, Zamora y Cañar, lugares donde se han dado inicio la pequeña minería y la extracción de minerales metálicos como el oro. Con el tiempo se ha ido desarrollando, no obstante, el daño ambiental es inminente.

Se ha venido utilizando el mercurio y últimamente el cianuro para procesos de refinamiento sin tomar las medidas adecuadas de remediación ambiental, lo que provoca contaminación de los suelos y las aguas en donde desechan todo el material inerte.

\section{Minería Artesanal}

Este tipo de minería se efectúa en casi todo el país porque los costos de inversión son bajos. Las herramientas de trabajo son accesibles al bolsillo de todos: pala, carretilla, platón, mercurio y sin contratación de personal.

Las consecuencias de esta minería es el impacto ambiental que genera, la falta de capacitación sobre este proceso y la utilización de reactivos que una vez aplicados son desechados en los mismos causes del río, contaminando el medio ambiente debido a la aplicación de cianuro y mercurio como agentes lixiviante del oro. (Abad Rominger, 2020)

Figura 1. Grupo de trabajadores desarrollando minería artesanal

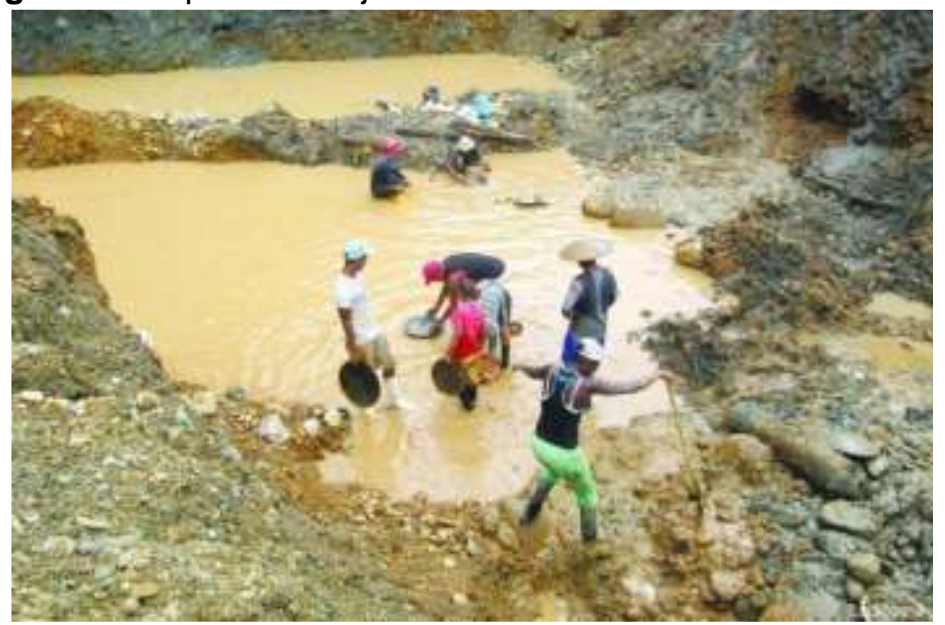

Fuente: "Evaluación de dos procesos de extracción de oro diferentes al de cianuración que cumplan las Normativas ambientales establecidas en Ecuador.' Abad Rominger, 2020 .

\section{Pequeña minería}

La aplicación de esta minería se da de una forma más organizada, por lo general la conforma entre 15 y 20 personas entre socios y trabajadores, quienes aportan de manera diferente con maquinarias, dinero y mano de obra, la organización es lo primordial en la pequeña minería, por lo cual la aplicación de esta se registra en la Subsecretaria de Minas y en la Agencia de Regulación y Control Minero (ARCOM), para poder trabajar de forma legal como lo estable la ley. (Abad Rominger, 2020) 
Figura 2. Pequeña minería

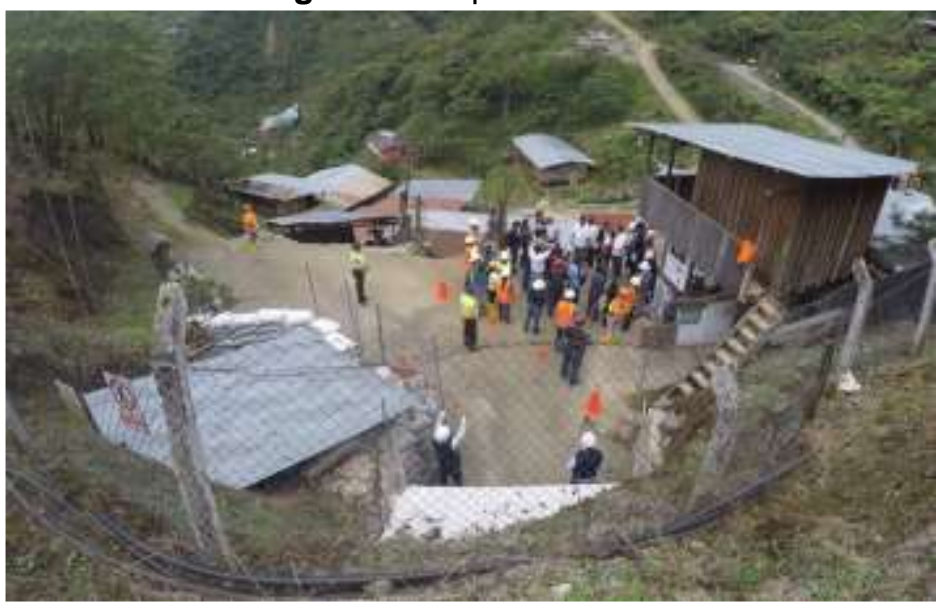

Fuente: "Evaluación de dos procesos de extracción de oro diferentes al de cianuración que cumplan las Normativas ambientales establecidas en Ecuador.' Abad Rominger, 2020 .

En esta minería cuando se trata de yacimientos subterráneos, los costos son más elevados porque deben dotarse de equipos que ayudan al trabajo en este ambiente, al igual en minería a cielo abierto en la cual extraen el material mediante excavadoras y demás equipos. (Abad Rominger, 2020)

\section{Métodos Físico - Químicas de Procesamiento Mineral Auríferos}

El mercurio es utilizado en la minería artesanal para procesar el oro, y parte de este mercurio es emitido produciendo graves en la salud humana e incluso daños al medioambiente.

Otros impactos provocados por la minería artesanal son la destrucción del paisaje, erosión del suelo, polución del aire con polvo, inadecuada eliminación de desechos industriales y domésticos (Costa et al., 2009). Ya que, por la baja tecnificación en las dosificaciones e implementación del método, genera una gran cantidad de inapropiados resultados.

Existen diferentes técnicas que ayudan a la disminución de la cantidad de mercurio utilizado en el proceso de recuperación de oro, y para determinar la mejor alternativa de recuperación de oro, se debe conocer los diferentes procesos, y tomando como base las propuestas de Castillo Sanchez (2018) de su trabajo de fin de grado Técnicas Alternativas para la extracción de oro sin el uso de mercurio y su potencial aplicación a pequeña escala y minería artesanal en Colombia, que están entre las más adecuadas y que son factibles en Ecuador son:

1. Técnicas Químicas
a. Bórax
b. Tiourea
c. Solventes orgánicos

2. Técnicas Físicas

a. Concentraciones gravimétricas 
- Separación por medio densos

- Separación por corrientes verticales

b. Flotación

- Separación en corrientes superficiales o flujo laminar

3. Técnicas Biológicas

a. Ochroma pyramidale

b. Bacterias

- Biolixiviación

- Biooxidación

Todas estas son analizadas desde diferentes puntos de vista según varios autores para establecer una relación amigable con el medio ambiente.

\section{Técnicas Químicas}

\section{a. Bórax}

El bórax, tetraborato de sodio, o borato de sodio es un cristal blanco soluble en agua, muy abundante en la tierra, se caracteriza por ser un semimetal y tiene la capacidad de disolver óxidos metálicos. El uso del bórax es muy común en la industria de la metalurgia por sus varios beneficios como desoxidante, material fundente y en aleaciones con materiales no ferrosos. De acuerdo con la clasificación de la norma NFPA 704 de la National Fire Protection Association, el bórax presenta un riesgo leve a la salud causando irritación o daños menores, aún en contacto prolongado con la piel, las vías respiratorias y los ojos; presenta alta estabilidad y no existen riesgos de inflamabilidad. (Castillo Sánchez, 2018)

Figura 3. Información técnica tetraborato de sodio
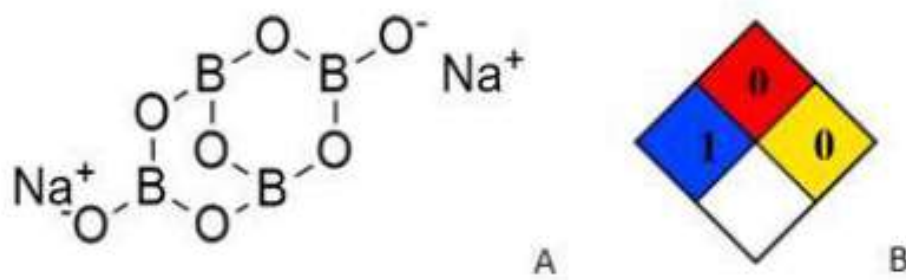

$\mathrm{Na}_{2}\left[\mathrm{~B}_{4} \mathrm{O}_{5}(\mathrm{OH})_{4}\right] \cdot 8 \mathrm{H}_{2} \mathrm{O}$

A) Estructura química, B) Símbolo de seguridad NFPA, C) Formula química

Fuente: "Técnicas alternativas para la extracción de oro sin el uso de mercurio y su potencial aplicación a pequeña escala y minería artesanal en Colombia' Castillo Sánchez, 2018, pág. 20

Al mezclarlo con otros compuestos puede resultar peligroso, como los pesticidas, por lo que se recomienda tomar las medidas de seguridad adecuadas.

El proceso de aprovechamiento de oro mediante el uso del bórax se da en etapas que contemplan: trituración y molienda en donde se disminuye el tamaño del material mediante el molino de bolas llegando a pulverizarlo, seguido por concentración gravimétrica se separa el material inerte, y en fusión directa con el bórax se satura el 
medio y se retira las partículas de oro atrapadas, se adiciona jabón para decantar las partículas de oro en suspensión. El material resultante se coloca a altas temperaturas hasta llegar al punto de fusión y separación de sus fases. (Castillo Sánchez, 2018)

En condiciones ambientales el punto de fusión del oro es de $1.063{ }^{\circ} \mathrm{C}$ y el del bórax de $743{ }^{\circ} \mathrm{C}$ (Hurlbut y Klain, 1997); sin embargo, una de las ventajas de esta técnica es la disminución del punto de fusión de toda la carga debido a que, al mezclarse con metales, el bórax actúa como catalizador. La menor temperatura de fusión permite la implementación de la técnica de manera fácil en áreas de difícil acceso y con recursos o equipos limitados, logrando rendimientos de alrededor del 97 \%. (Castillo Sánchez, 2018)

\section{b. Tiourea}

La Tiourea (TU) o tiocarbamida es el agente lixiviante que mayores ventajas tiene, por ser amigable con el ambiente, es soluble, y niveles menores de toxicidad con un riesgo moderado.

Figura 4. Información técnica tiocarbamida

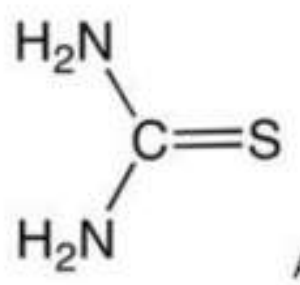

A) Estructura quimica,

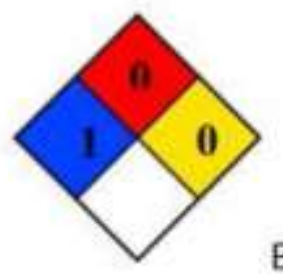

B
$\mathrm{CH}_{4} \mathrm{~N}_{2} \mathrm{~S}$

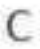

Fuente: “Técnicas alternativas para la extracción de oro sin el uso de mercurio y su potencial aplicación a pequeña escala y minería artesanal en Colombia' Castillo Sánchez, 2018, pág. 23

En la recuperación de oro al mezclarse con oro forma complejos que se denominan tiureatos, dando las mejores ventajas operacionales. (Abad Rominger, 2020) Además, requiere un control de parámetros físico-químicos que son: $\mathrm{pH}$, potencial Redox, concentración de la Tiourea, concentración del agente oxidante, si se controla todos estos parámetros se alcanzará un $96 \%$ de rendimiento del oro en mineral y se trabaja en las siguientes condiciones: (Castillo Sánchez, 2018)

- Medio ácido, pH entre 1.5 y 3.

- Usar varios agentes oxidantes, como el Fe+3

- La disolución del oro produce un compuesto catiónico a diferencia del cianuro que produce compuestos aniónicos.

\section{c. Solventes Orgánicos}

Se han realizado varios estudios de procesos de lixiviación alternativos para limitar el uso del mercurio, dentro de las que se encuentran ligados orgánicos, amoniaco, compuestos 
halogenados, ácido clorhídrico, entre otros; sin embargo, el éxito de aplicación de estas técnicas depende del control estricto de las variables, que mayormente se pueden obtener en laboratorio, convirtiéndolas en técnicas costosas y poco prácticas. (Castillo Sánchez, 2018)

\subsection{Técnicas Físicas}

a) Cribado, Concentración Gravimétrica o Gravitacional, que se efectúa por la diferencia de los pesos específicos de los materiales, siendo el oro el mineral con mayor densidad, el cual se concentrará más fácilmente en las bateas o bayetas que atrapan a las partículas pesadas, mientras que las menos densas tendrán otro proceso.

Los métodos de separación gravimétrica en 3 categorías de acuerdo con el principio de funcionamiento: Separación por corrientes verticales (diferencias de velocidad de sedimentación), separación por medios densos (el material aurífero se sumerge en un medio de densidad conocida) y separación en corrientes superficiales o películas (se basa en un el flujo laminar de agua en películas muy delgadas, con superficies ligeramente inclinadas sobre las cuales se aplican fuerzas externas que permiten la separación de materiales por diferencia de densidades, se usa equipos como las mesas vibratoria o concentradores, concentradores en espiral, centrífugas, jig, etc.; siendo el primer equipo el más representativo y de mayor uso por su versatilidad y eficiencia de operación). (Castillo Sánchez, 2018).

Figura 5. Concentrado de oro

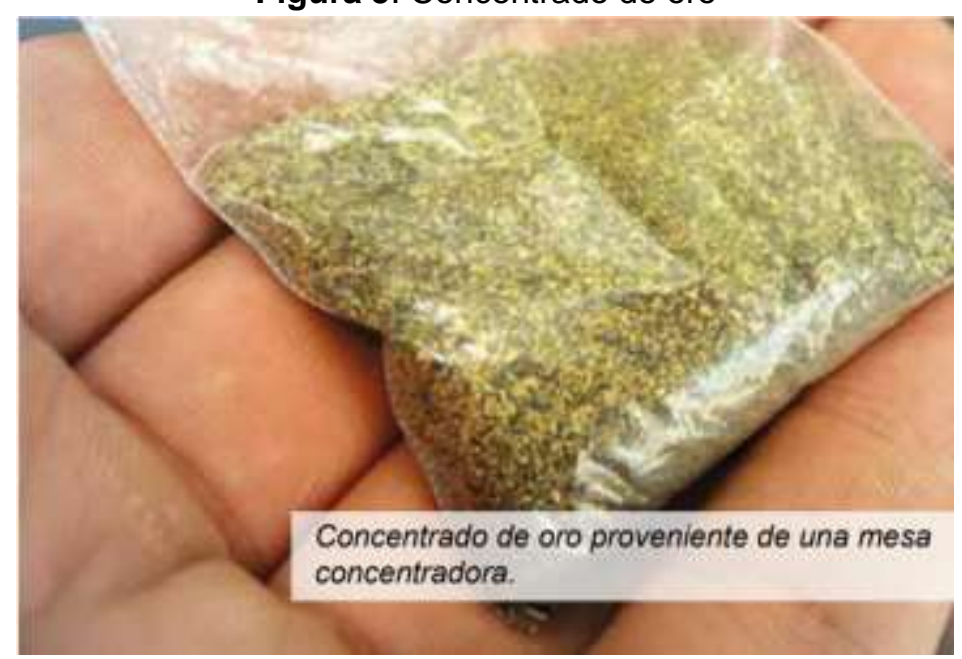

Fuente: “Guía Práctica del uso de mercurio en la minería de oro artesanal y de pequeña escala". Producido por Artisanal Gold Council (AGC) y con la asistencia de la ONUDI, la Universidad de Victoria y la Unión Internacional de Ciencias Geológicas-Comisión de Geociencias para la Gestión Ambiental (IUGS-GEM); 2012.

b) Flotación, es un método físico-químico de superficie en el cual el material o pulpa llega desde el proceso de molienda a la celda o tanque de flotación, en procesado 
por la inyección de una espuma que generan burbujas de variado tamaño, en las cuales se adhieren selectivamente las partículas minerales; proceso que genera una espuma rica en mineral de interés que sube a la superficie del tanque o celda, para recogida y concentrada en los concentrados. Estas burbujas contienen los minerales de interés en este caso oro y cobre, se almacenan en la superficie de la pulpa formando una espuma la cual se va recogiendo poco a poco mientras los demás minerales permanecen sumergidos constituyendo las colas y relaves. (Abad Rominger, 2020)

Figura 6. Diagrama del proceso de flotación

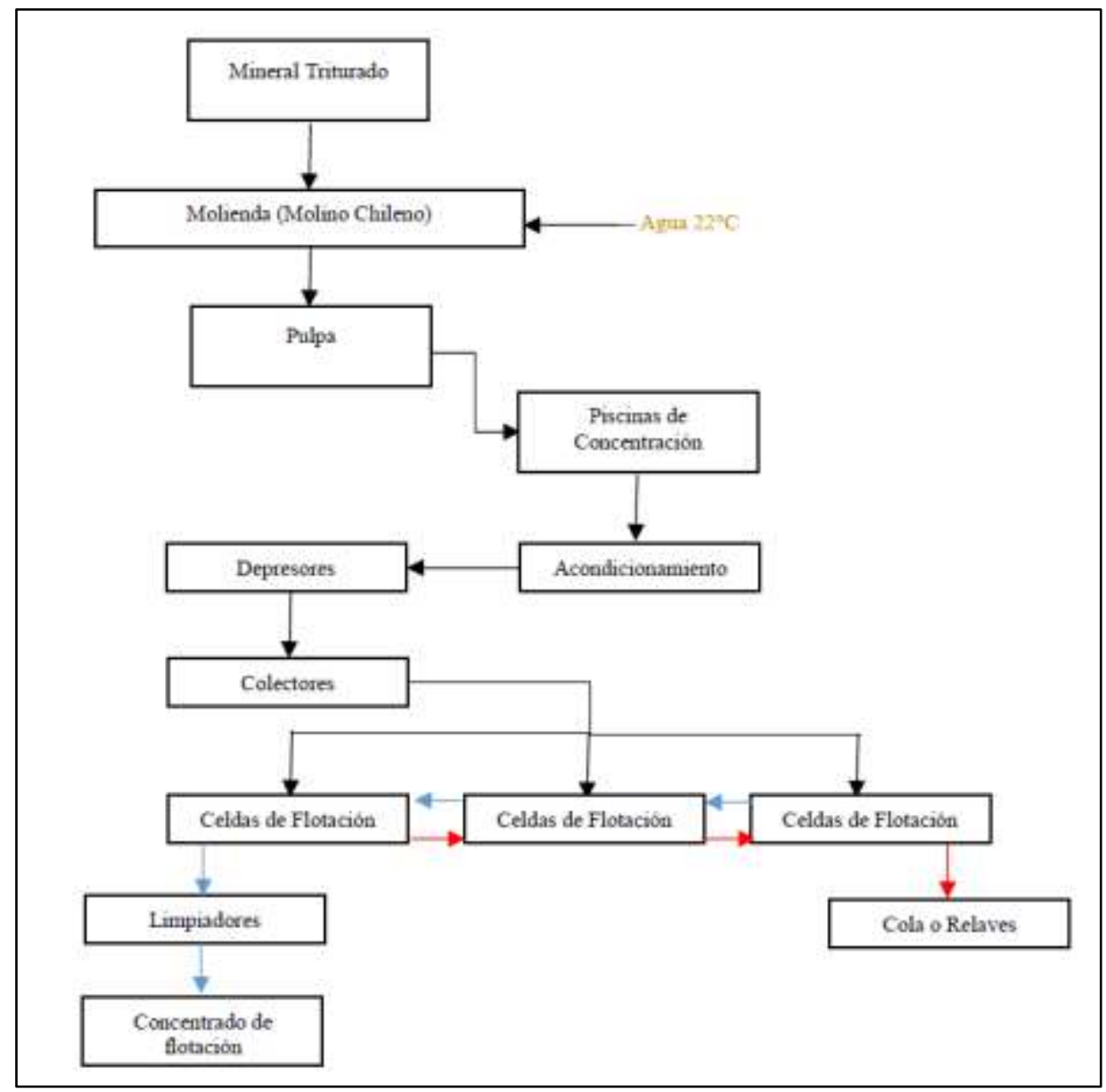

Fuente: "Evaluación de dos procesos de extracción de oro diferentes al de cianuración que cumplan las Normativas ambientales establecidas en Ecuador." Abad Rominger, 2020.

\section{Técnicas Biológicas}

\section{a) Ochroma pyramidale}

Este es un árbol de balsa, guano o ceiba de lana (Ochroma pyramidale) que tiene propiedades de densidad, ligereza y flotabilidad, es decir propiedades amalgamantes, que le permite ser empleada en diferentes industrias.

El empleo de esta técnica se llama "Oro Verde", y consiste en utilizar extracto de plantas disponibles localmente. Las hojas de Balsa (Ochroma pyramidale) y 
Malva (Hibiscus furcellatus) se trituran a mano y se mezclan con agua para hacer un líquido espumoso que se agrega a la bandeja de oro (batea) en lugar de mercurio. Empleando el mismo principio de la técnica de flotación descritas en el literal b) de las técnicas físicas, la mezcla babosa del extracto rompe la tensión superficial del agua y permite la precipitación del oro de grano muy fino, magnetita y otros minerales pesados; mientras que los minerales más ligeros son separados del oro por la diferencia de densidad (Brooks et al., 2015).

Figura 7. "Oro Verde"

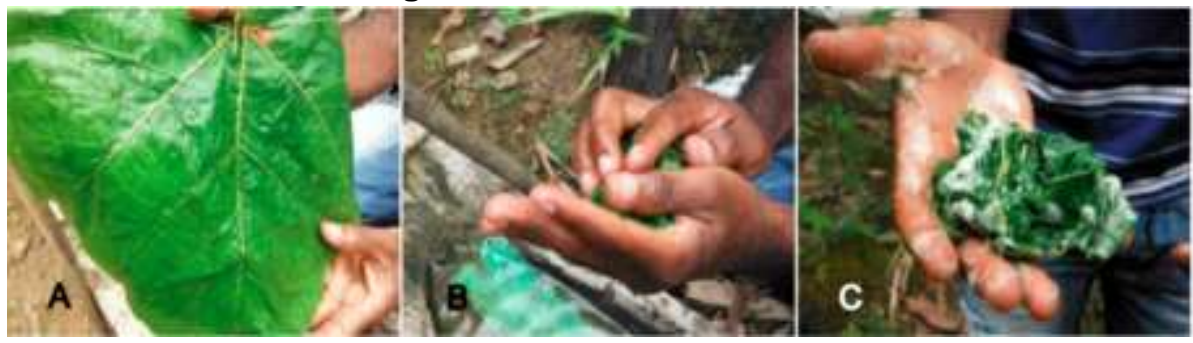

Fuente: "Técnicas alternativas para la extracción de oro sin el uso de mercurio y su potencial aplicación a pequeña escala y minería artesanal en Colombia.," Castillo Ivan, 2018.

\section{b) Bacterias}

En el año 1947 que se iniciaron las primeras investigaciones con bacterias acidófilas aplicadas a la minería, las cuales tienen la capacidad de obtener la energía necesaria para sus procesos metabólicos a partir de la oxidación y hierro y azufre (Cortón y Saavedra, 2014). Industrialmente, se han implementado dos procesos que utilizan microorganismos para la extracción de metales preciosos o facilitan y mejoran su recuperación (Misari Chuquipoma, 2016).

\section{- Biolixiviación}

La biolixiviación es el proceso mediante el cual se solubiliza el metal por la catálisis que los microorganismos ejercen a través de la transferencia de electrones, convirtiéndolos en compuestos metálicos solubles en agua. La formación de cianuro (cianogénesis), se da como metabolito secundario y se presume que es con el fin de inhibir organismos competidores (Brandl et al., 2004). El uso de organismos cianogénicos se ha empleado con éxito en industrias mineras para la lixiviación de oro, reduciendo los riesgos ambientales asociados a los métodos tradicionales de lixiviación de oro, ya que el cianuro producido por las bacterias es de naturaleza volátil y puede reducirse fácilmente en presencia de sales y otros compuestos presentes en el medio de crecimiento (Ilyas y Lee, 2018).

- Biooxidación

En la biooxidación, los minerales de sulfuro que conforman el material aurífero, son oxidados por microorganismos empleando el hierro y azufre 
elemental para formar sulfatos metálicos solubles y producir ácido sulfúrico (Ilyas y Lee, 2018). Para el caso del oro, cuando este se encuentra asociado a minerales sulfurados como la pirita o arsenopirita, esta es solubilizada por microorganismos con el fin de dejar libre el oro. Posteriormente es recuperado a través de la implementación de alguna técnica de concentración (Cortón y Saavedra, 2014)

\section{Problemas medioambientales generados por la minería artesanal y pequeña minería}

En el punto 6 de este artículo se desarrolla el concepto de lo que es minería artesanal y pequeña minería. Existen dos formas de extracción; subterránea y a cielo abierto. La primera es menos grave que la de superficie, aunque su incidencia en enfermedades a las personas expuestas es mayor (Espinoza Aguilar, 2016).

Por otro lado, existe un impacto sobre el medio ambiente cuando una acción o actividad produce una alteración, favorable o desfavorable en el medio. La explotación superficial genera un mayor impacto en el medio ambiente, con destrucción de suelos naturales y creación de otros nuevos con fuertes limitaciones físicas, químicas y biológicas que dificultan la reimplantación de la vegetación (Espinoza Aguilar, 2016).

Los impactos ambientales más relevantes en el proceso minero, corresponden a la modificación del paisaje, la acumulación de estériles, destrucción de la flora y fauna, lixiviación, contaminación del agua cuando el lecho de una escombrera es excesivamente permeable y cuando el material depositado tiene altas concentraciones de sustancias hidrosolubles y/o metales pesados como el Mercurio y cianuro.

Según Pérez y Betancur (2016), Es importante tener presente que, para lograr un procesamiento de metales efectivo, se deben utilizar diversos productos químicos como mercurio, cianuro, ácidos concentrados y demás, lo cual altera y contamina el ciclo hidrológico afectando ecosistemas fluviales y terrestres, ya que todo ser vivo depende del agua y requiere para su sostenimiento un mínimo vital.

Por otra parte, y como ejemplo, la contaminación que ha atacado a los afluentes se ha venido desarrollando en la provincia de El Oro, "debido a los altos índices de contaminación en los cursos de agua existentes en la parte alta de la cuenca PuyangoTumbes, que comparten Ecuador y Perú relacionados con el desarrollo de la actividad minera aurífera a pequeña escala y artesanal” (EC Ministerio del Ambiente 2011).

A saber, Zorrilla un activista que es Co-fundador de la DECOIN, de la Asociación de Caficultores de Intag y de la Red Nacional de Bosques Privados expone en su publicación "Autodidacta en impactos de la minería a gran escala" que, la minería moderna utiliza y contamina enormes cantidades de agua. Para producir una tonelada de cobre puro se requiere decenas de miles de litros de este vital recurso diariamente (Vilela et al., 2020).

Por ejemplo, el proyecto minero cuprífero El Mirador, en Zamora Chinchipe, prevé utilizar cerca de 12 millones de litros por día solo para explotar y concentrar el equivalente 
a 200 toneladas cobre (promedio de 60.000 litros/Tn) al día. Sin duda, el problema nace de la falta de cumplimiento de las regulaciones existentes que, en gran parte de los casos, no se cumplen generando enormes volúmenes de agua contaminada que afecta no solo al ecosistema a lo largo del efluente si no también al ser humano que se sirve de los mismos (Vilela et al., 2020).

Los impactos ambientales generados en la etapa de refinación de minerales se encuentran relacionados con las emisiones atmosféricas (dióxido de Azufre, mercurio volátil, material particulado, entre otros) y la generación de escorias. En la fundición de metales, el efecto que causa mayor preocupación es la contribución de óxidos de azufre en la formación de lluvia ácida (Vilela et al., 2020).

Figura 8. Proceso de fundición con evaporación de metales

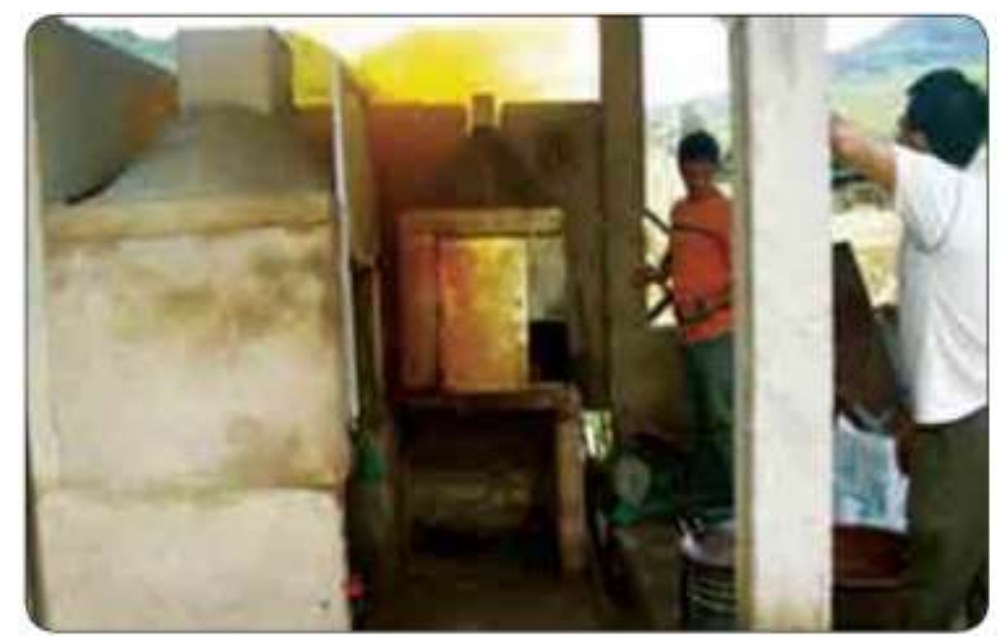

Fuente: “Propuesta de gestión integral para los procesos de explotación de la minería artesanal'” Espinoza Aguilari, 2016.

\section{Propuestas}

Se ha descrito en este artículo los grupos de técnicas de extracción de oro, siendo estas físicas, químicas, biológicas y una combinación de éstas. Todas estas representan alternativas al uso del mercurio para procesar y extraer oro que tendrán un impacto menor al medio ambiente y también al minero artesanal y pequeño minero.

El autor propone el uso de alternativas verdes como primera opción debido a su reducido impacto en el ambiente. Siendo en algunos casos necesario "cultivar" el material amalgamante, ya sean estos bacterias o plantas. El residuo será de fácil disposición ya que no generará ningún material peligroso contra la salud o el medioambiente. Los individuos que se dedican a la minería artesanal se verán positivamente afectados debido a que no se expondrá a agentes altamente contaminantes como el mercurio o cianuro.

En la mayoría de los casos aquí descritos, el impacto al medio ambiente es nulo desde el punto de vista de contaminación, aunque puede manifestarse de otra manera como deforestación excesiva de balsa como material amalgamante, por ejemplo. 
Como una opción alterna e igualmente positiva, se recomienda priorizar el uso de técnicas físicas de cribado o concentración gravimétrica. Que no representan una amenaza de contaminación al medio ni al ser humano, aunque precisa de grandes volúmenes de agua para poder desarrollar una extracción eficiente. El desarrollo de este tipo de extracción es aconsejable para proyectos de pequeña minería que estén localizados en zonas con abundante disponibilidad del recurso hídrico; de otra forma, el desarrollo del método podría representar un riesgo para el suministro local de agua, afectando a sembríos y a la crianza de animales.

\section{Discusión}

La selección de un método que sea técnica y económicamente viable que reemplace el uso de mercurio o cianuro en el desarrollo de minería artesanal y pequeña minería, y que además sea sustentable en el tiempo, es dependiente de varios factores; entre ellos, el volumen de mineral a procesar, disponibilidad de recurso hídrico, costo de aplicar la técnica, grado de eficiencia que se espera luego de la extracción de oro y el grado de apoyo que logre de entidades estatales o auspiciantes privados.

Por un lado, la alternativa biológica, con el empleo de hojas de balsa, se restringe a pequeñas cantidades de mineral. Como ejemplo, se cita que en Colombia se procesa 6 $\mathrm{kg} / \mathrm{año}$ de oro cuando en la pequeña minería se llega a procesar hasta $500 \mathrm{~kg} / \mathrm{año}$ mediante técnicas como el uso de mercurio. Evidentemente, la técnica no puede competir con la extracción con mercurio cuando se trata de procesar grandes volúmenes. Una forma de aumentar la capacidad de procesamiento sería constituir facilidades a mayor escala que necesariamente dependen de mayor inversión y por ende menor rendimiento.

El uso de bacterias por otro lado representa grandes inversiones debido a que la técnica debe ser controlada y las variables involucradas deben ser cuidadosamente vigiladas. Puede ser la ideal pero no necesariamente la más factible. Se esperaría que el uso de estos métodos "libres de contaminación" sean apoyados y estimulados por entes estatales para poder hacer competitivo al minero artesanal que quiera optar por esta técnica.

En cuando al método de cribado, se destaca la necesidad de grandes volúmenes de agua que necesitan regulación de entes de control y cumplimiento de las normas. En Ecuador, las zonas mineras que están en las estribaciones de la cordillera serían ideales para el empleo de este método. Sin embargo, es recomendable el acompañamiento de entes de control estatal para la verificación de que el agua utilizada en estas actividades no sufra la contaminación con químicos peligrosos.

Los métodos químicos por otro lado, representan un riesgo mayor para el medioambiente ya que un uso poco controlado y en contacto con otras sustancias puede producir sustancias que representen un riesgo para la salud humana y para el medio ambiente. Se plantea su uso en el caso de que el personal involucrado tenga un correcto entrenamiento en el manejo de sustancias químicas. 


\section{Conclusiones}

- En el desarrollo económico del Ecuador, toma relevancia la extracción de sus depósitos de oro y polimetálicos. En el mundo actual, toma una gran importancia que esa extracción sea amigable con el ambiente y genere sobre él, el menor impacto posible. Ya que el uso tradicional de mercurio para la extracción de Oro en Ecuador, ha generado graves daños al medio ambiente y al ser humano, en algunos casos de forma irreparable, por lo que se propone un cambio de rumbo hacia una extracción más sostenible sin que deje de ser rentable.

- El medio ambiente es un tema actual que genera mucha polémica cuando se trata de la actividad minera, no obstante, se ha consolidado el análisis de varios mecanismos con una disminución sustantiva del impacto al ambiente, pero que preservan su eficacia en la extracción mineral. Existen métodos alternativos al uso de mercurio y cianuro cuyo impacto al medio ambiente es menor. Su aplicabilidad y éxito, dependerá de varios factores como, recursos económicos para la implementación, localización geográfica del proyecto y formación/experiencia del minero artesanal o pequeño minero que quiera aplicarlo; pero de manera primordial, depende de la naturaleza del mineral de mena y ganga a procesar.

- El oro elemental se presenta en la naturaleza de diversas maneras dependiendo desde su número de valencia como de su ocurrencia mineral, dándole características físicas y químicas propias, que desembocan en la necesidad innata de métodos extractivos puntuales y variados para cada situación.

- De manera estándar, se tiene que al encontrar manifestado en partícula libre y de gran tamaño, el método indicado sería la concentración de este elemento por métodos gravitacionales. Si de forma homóloga elemento oro se encuentra ocluido, asociado o dentro de la red cristalina de mineral sulfurado, el método idóneo recomendado sería el de Flotación, concentrando de primera mano minerales como pirita o pirrotina, sulfuros que por su metalogénesis han albergado por diferentes vías las partículas de oro. Por otro lado, si el oro se encuentra en las fases de un mineral oxidado, éste oro principalmente puede ser tratado por métodos químicos lixiviantes.

- Luego de la investigación realizada, se recomienda tomar cada uno de los métodos y realizar una investigación detallada de su aplicación y como implementarlo en la minería artesanal y pequeña minería.

\section{Referencias bibliográficas.}

Abad R. (2020). "Evaluación de dos procesos de extracción de oro diferentes al de cianuración que cumplan las Normativas ambientales establecidas en Ecuador'. Universidad Técnica de Machala. http://repositorio.utmachala.edu.ec/handle/48000/15483

Brooks, W.E., Schworbel, G. and Castillo, L.E. (2011) Amalgamation and Small-Scale Gold Mining in the Ancient Andes. Bulletin de l'Institut Francais d'études Andines, 40, 333-349. http://dx.doi.org/10.4000/bifea.1471 
Castillo I. (2018). Técnicas alternativas para la extracción de oro sin el uso de mercurio y su potencial aplicación a pequeña escala y minería artesanal en Colombia. Trabajo de grado para optar al título de ingeniero ambiental. https://repository.unad.edu.co/handle/10596/21703

Costa M., Alfonso P., \& Palacios S. (2009). Proceso de tratamiento para la recuperación de oro en el asentamiento minero artesanal de Misky. Segundo Congreso Internacional sobre Geología y Minería en la Ordenación del Territorio y en el Desarrollo. Archivo digital. https://upcommons.upc.edu/bitstream/handle/2117/115922/20.UTRILLAS.pdf?s equence $=1 \&$ isAllowed $=\mathrm{y}$

Enciclopedia de Salud y Seguridad en el Trabajo, (2018). Gestión Editorial Chantal Dufresne, BA.

http://www.cucba.udg.mx/sites/default/files/proteccioncivil/normatividad/Encicl opedia\%20de\%20salud \%20y\%20seguridad\%20en\%20el\%20trabajo.pdf

Espinoza Aguilar, Y. P. (2016) Propuesta de gestión integral para los procesos de explotación de la minería artesanal. Universidad Técnica de Machala. Archivo digital. http://www.uagraria.edu.ec/publicaciones/revistas_cientificas/quinta-ola1/CIEA-EA-GMA-004.pdf

López J. \& Moreno R. (2018). Sostenibilidad de la extracción Minera del Oro Implementando controles Estatales. Trabajo de grado para obtención de título de Economista. Universidad Católica de Colombia. Bogotá. Archivo digital.

Murillo Stephanie \& Gazel Esteban, (2019). Cianuro vs. Mercurio: la diferencia entre la industria mineral responsable y la mineral ilegal. https://delfino.cr/2019/01/cianuro-vs-mercurio-la-diferencia-entre-la-industriamineral-responsable-y-la-mineral-ilegal

Rizo J. (2015). Técnicas de Investigación Documental. Universidad Autónoma de Nicaragua. Nicaragua: Matagalpa. https://repositorio.unan.edu.ni/12168/

Tsenkush F., (2016). "Evaluación de las reservas de Oro (Au) en las Terrazas eluviales del Sector San Vicente”. Trabajo de grado para obtención de título de Ingeniero en Geología y Minas. Escuela Superior Politécnica de Chimborazo.

Vilela-Pincay, W., Espinosa-Encarnación, M., \& Bravo-González, A. (2020). La contaminación ambiental ocasionada por la minería en la provincia de El Oro. Estudios De La Gestión: Revista Internacional De administración, (8), 210-228. https://doi.org/10.32719/25506641.2020.8.8

Zorrilla C. (2013) Autodidacta en impactos de la minería a gran escala. 


\section{PARA CITAR EL ARTÍCULO INDEXADO.}

Granja Carrera, J. P., Ordoñez Guaycha, C. A., \& Cuesta Andrade, G. G. (2021). Análisis aplicativo de mecanismos para la recuperación de Oro y polimetálicos, en el ámbito de la pequeña minería y minería artesanal en Ecuador, amigables con el medio ambiente. AlfaPublicaciones, 3(3.1), 271-288. https://doi.org/10.33262/ap.v3i3.1.92

\section{LCiencia}

El artículo que se publica es de exclusiva responsabilidad de los autores y no necesariamente reflejan el pensamiento de la Revista Alfa Publicaciones.

El artículo queda en propiedad de la revista y, por tanto, su publicación parcial y/o total en otro medio tiene que ser autorizado por el director de la Revista Alfa Publicaciones.
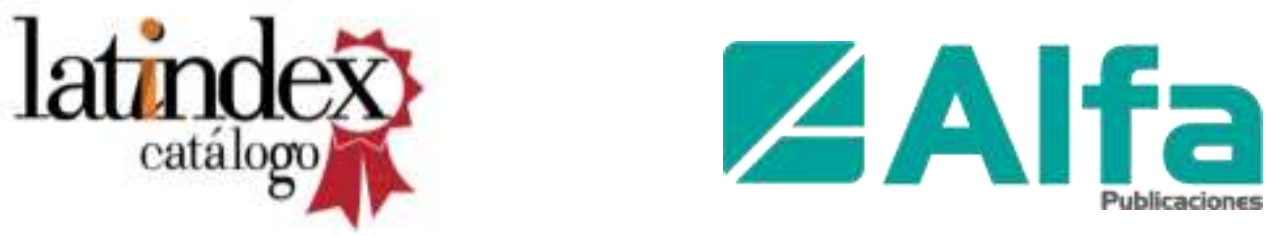